\title{
Alternaric acid: formal synthesis and related studies
}

\author{
Michael C. Slade and Jeffrey S. Johnson
}

\author{
Full Research Paper \\ Address: \\ Caudill Laboratories, Department of Chemistry, University of North \\ Carolina at Chapel Hill, Chapel Hill, NC 27599-3290, USA \\ Email: \\ Jeffrey S. Johnson* - jsj@unc.edu \\ * Corresponding author \\ Keywords: \\ formal synthesis; multicomponent coupling; natural products; silyl \\ glyoxylates
}

Open Access

\author{
Beilstein J. Org. Chem. 2013, 9, 166-172. \\ doi:10.3762/bjoc.9.19 \\ Received: 24 October 2012 \\ Accepted: 20 December 2012 \\ Published: 24 January 2013 \\ This article is part of the Thematic Series "Creating complexity". \\ Guest Editor: D. Craig \\ (C) 2013 Slade and Johnson; licensee Beilstein-Institut. \\ License and terms: see end of document.
}

\begin{abstract}
A silyl glyoxylate three-component-coupling methodology has been exploited to achieve a formal synthesis, an analogue to an intermediate in a distinct formal synthetic route, and a third (unique) approach to the natural product alternaric acid. Highlighted in this study is the versatility of silyl glyoxylates to engage a variety of nucleophile and electrophile pairs to provide wide latitude in the approach to complex molecule synthesis.
\end{abstract}

\section{Introduction}

The rapid development of molecular complexity from simple starting materials is an important goal in modern synthetic organic chemistry. In this context, streamlined one-pot transformations, cascade reactions, and multicomponent couplings have emerged as enabling tools for the synthesis of complex molecules [1,2]. Our laboratory [3-16] and others have developed [17] and employed [18,19] silyl glyoxylates $\mathbf{1}$ in a variety of synthetic endeavors, both in natural-product synthesis and synthetic methodologies [20]. Key to their use in a variety of contexts is the ability of silyl glyoxylates to function as linchpin synthons for geminal coupling of nucleophile/electrophile pairs at a glycolic acid subunit (Scheme 1A), which allows the rapid build-up of molecular complexity. Alternaric acid (2) [21-23] is an antifungal and phytotoxic natural product, which bears a substituted glycolic acid in the functionally and stereochemi- cally dense core of the molecule; the potential application of silyl glyoxylate technology emerged as an attractive starting point for synthetic planning (Scheme 1B). This paper summarizes our synthetic work in this arena, which culminated in a formal synthesis, an analogue of another formal synthesis, and a unique approach to the target; each of the routes was enabled by distinct coupling partners.

Alternaric acid is a particularly interesting target to demonstrate the utility of silyl glyoxylates, as it has been the subject of one total synthesis [24], one formal synthesis [25], and a potential application of an asymmetric glycolate aldol methodology [26]. These precedents serve as fruitful comparison points for application of a silyl glyoxylate three-component coupling methodology. Scheme 2 highlights three potential avenues 
A)

$\mathrm{Nu}^{\ominus}+$<smiles>[R9]C(=O)C(=O)[AlH2]</smiles>

Viable Nucleophiles:

$\overbrace{\mathrm{R}^{\prime}}^{\mathrm{O}^{-M g X}}$ or $\mathrm{Et}_{2} \mathrm{Zn}\left[\begin{array}{c}\text { as a source of } \\ \mathrm{H}^{-}\end{array}\right]$ $\widehat{C}_{\mathrm{MgBr}},{ }^{\mathrm{Me}}{ }_{\mathrm{MgBr}}, \mathrm{R}=\mathrm{MgBr}$ $\mathrm{R} \equiv \mathrm{Znl}, \cong \mathrm{ZnBr} \quad \mathrm{Ar}$

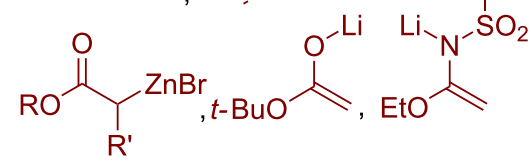

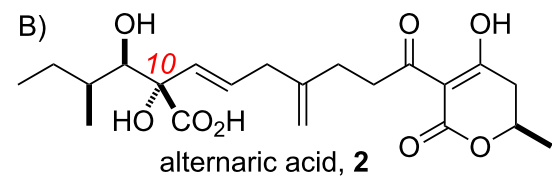

$E I^{\oplus}$<smiles>C1CC1</smiles>

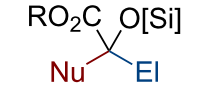

Viable Terminal Electrophiles:<smiles>[R]C=O</smiles><smiles>[R]C([R])=O</smiles><smiles>[R]C=C[N+](=O)[O-]</smiles><smiles>[R]C=N[S@](=O)C([Y])(C)C</smiles>

therefore,<smiles>[R9]C(=O)C(=O)[SiH3]</smiles>

can be viewed as a<smiles>[N+]=[N+]CC[Te][Te](=O)(O)O</smiles>

versatile glycolic acid linchpin

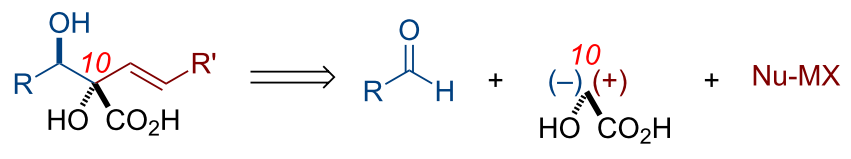

Scheme 1: (A) Silyl glyoxylates as versatile reagents for three-component coupling reactions: representative nucleophiles and electrophiles. (B) Alternaric acid as a potential application of a silyl glyoxylate-enabled three-component coupling reaction.

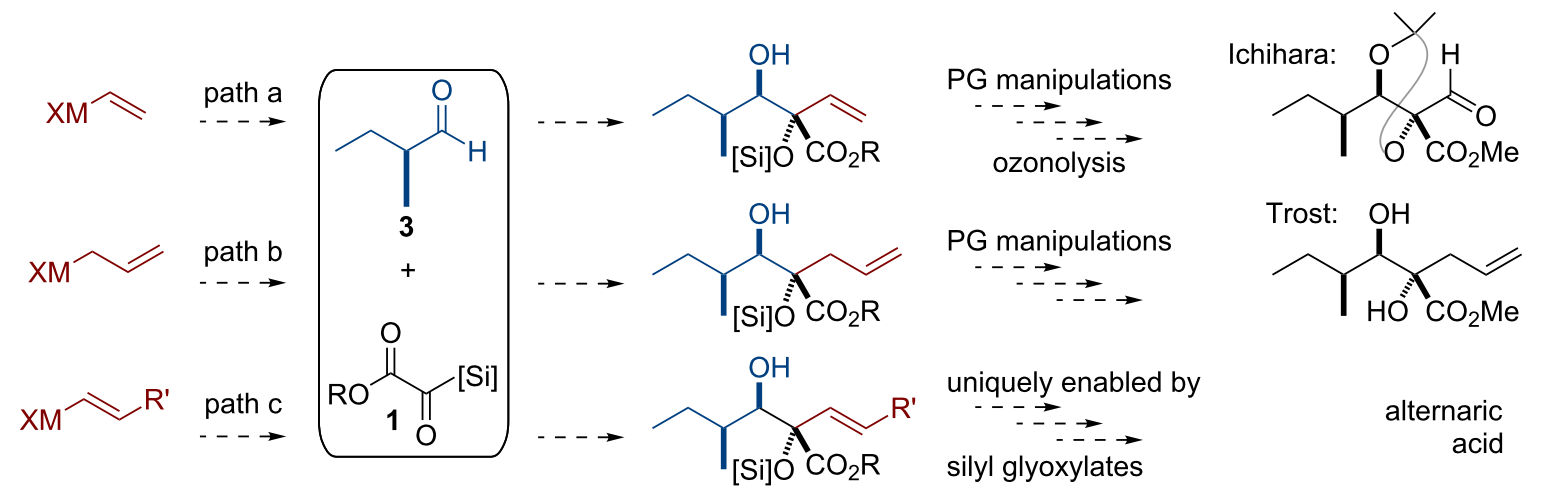

Scheme 2: Potential applications of silyl glyoxylate couplings and precedent synthetic intermediates toward the synthesis of alternaric acid.

toward the natural product and their precedents, by using the readily available (S)-2-methylbutanal (3) [27] and silyl glyoxylates $\mathbf{1}$ as two of the three key components for a coupling reaction.

\section{Results and Discussion}

Synthetic studies were initiated to explore paths $a$ and $b$ in Scheme 2, given the perceived rapidity with which the known intermediates could be intercepted after the proposed threecomponent coupling reactions. These initial studies revealed a limitation to this approach, inherent in the use of aldehyde $\mathbf{3}$ as a coupling partner: inherently poor Felkin-Anh facial selectivity with respect to the aldehyde electrophile due to minor differentiation between the Et/Me groups [28-30]. In all cases, the facial selectivity was rather poor, i.e., approximately 1.7:1, regardless of nucleophile, counterion, solvent, and temperature. Brief optimization efforts for each nucleophile thus focused on maximizing the coupling efficiency and syn-/anti-aldol selectivity (see Supporting Information File 1).

The optimal conditions for use of a vinyl nucleophile involved addition of a solution of vinylmagnesium bromide (4) and (-)-sparteine [31] in toluene to a solution of the tert-butyl silyl glyoxylate 1a and (S)-2-methylbutanal (3) in toluene at $-78{ }^{\circ} \mathrm{C}$ followed by warming to room temperature, which provided the three-component-coupling product 5 with excellent $(>20: 1)$ syn-/anti-aldol selectivity in 65\% yield (Scheme 3). Ichihara's aldehyde intermediate could be intercepted in three additional 


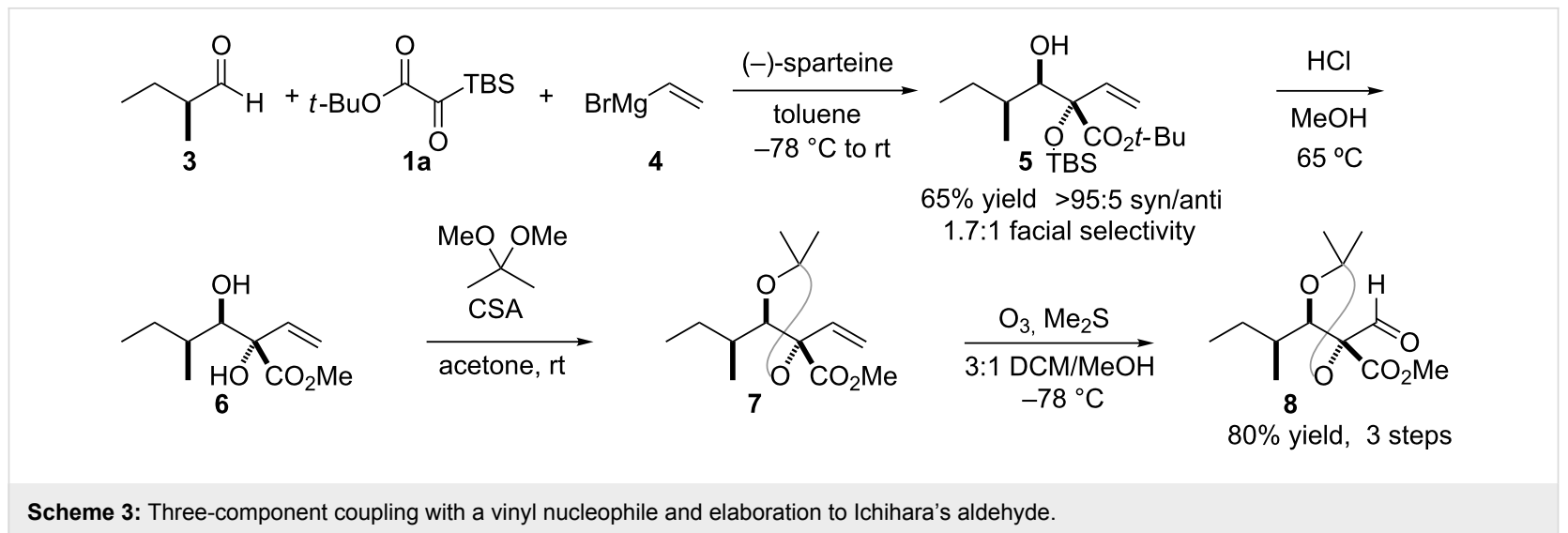

steps, in high overall yield. Simultaneous cleavage of the silyl ether and transesterification from the tert-butyl to the methyl ester in $\mathbf{6}$ was effected by warming in acidic methanol. Subsequent acetonide formation provided 7, and ozonolysis afforded Ichihara's aldehyde 8 (Scheme 3 ).

Interception of this intermediate thus constituted a formal synthesis; the precedent for the $\mathrm{C} 8 \mathrm{-C} 9$ olefination involved a classical, three-step Julia olefination sequence [24]. To demonstrate proof-of-concept for a more step-efficient endgame, test substrates were prepared for exploration of a modified Julia olefination [32]. As shown in Scheme 4, the phenyltetrazole heteroaromatic core in sulfones $9 \mathbf{a}$ and $\mathbf{9 b}$ provided excellent $E$-/Z- selectivity for formation of the C8-C9 olefin under typical modified Julia conditions with no optimization necessary. In particular, the vinyl bromide functional handle in $\mathbf{1 0 b}$ provides a potential avenue for elaboration to the natural product.

With the promise of the approach thus demonstrated involving the use of the vinyl nucleophile, attention shifted toward exploration of the allyl nucleophile. The best conditions for the use of an allyl nucleophile involved the addition of allylzinc bromide
(11) in THF to a THF solution of benzyl silyl glyoxylate $\mathbf{1 b}$ and (S)-2-methylbutanal $(3)$ at $0{ }^{\circ} \mathrm{C}$ followed by warming to room temperature (Scheme 5). In the event, the three-component coupling product 12 was in $50 \%$ combined yield of all four possible diastereomers: 3.6:1 syn-/anti-selectivity and $\sim 1.7: 1$ facial selectivity were observed. Thus, under these conditions both the control of enolate geometry as well as facial selectivity with respect to the aldehyde were incomplete. The four diastereomers could only be separated into syn/anti sets; within each set, the Felkin/anti-Felkin diastereomers could not be separated.

As with three-component coupling product 5, advancement of intermediate 12 proved straightforward (Scheme 5). Deprotection of the silyl ether with TBAF afforded diol 13, which is a benzyl ester analogue of one of Trost's substrates employed in the ruthenium-catalyzed Alder-ene reaction [25]. It too proved to be a successful substrate for the reaction with alkyne $\mathbf{1 4}$, affording the 1,4-diene product $\mathbf{1 5}$ in $52 \%$ yield. This sequence thus demonstrated a second avenue for successful exploitation of a silyl glyoxylate coupling methodology to achieve a stepefficient approach toward the assembly of the carbon skeleton of alternaric acid.

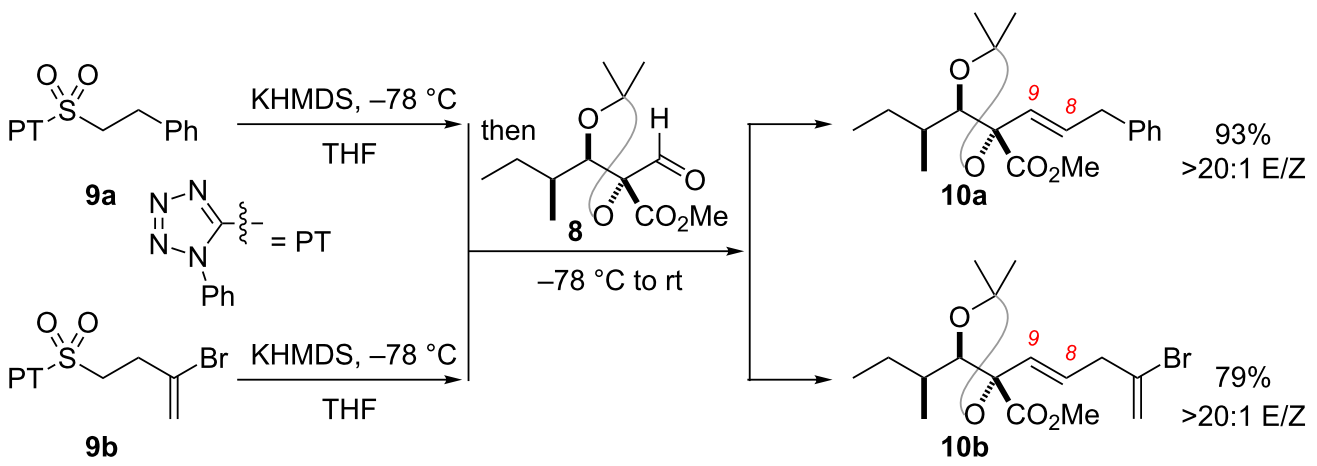




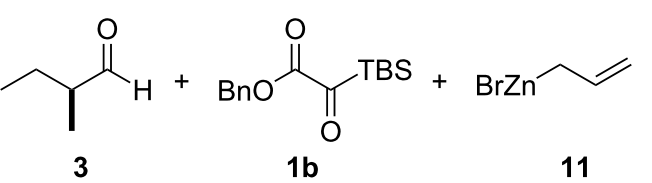

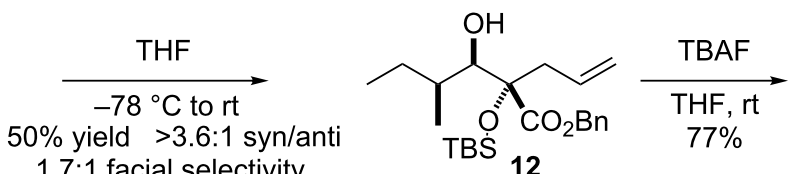<smiles>C=CCC(O)(C(=O)OBr)C(O)C(C)CC</smiles>

13<smiles>C#CCCC(=O)OCC</smiles>

$\mathrm{Fm}=9$-fluorenylmethy

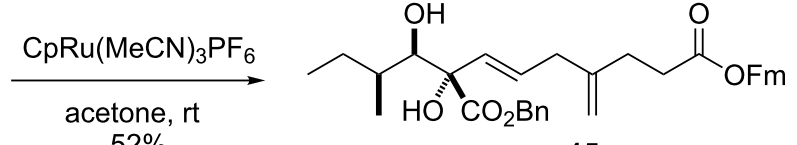

15

Scheme 5: Three-component coupling with an allyl nucleophile and demonstration of successful ruthenium-catalyzed Alder-ene approach.

The two approaches described above both highlighted an important limitation to the use of $(S)$-2-methylbutanal (3) as the third component in the silyl glyoxylate-based threecomponent coupling reaction: while this aldehyde directly affords the substructure of the natural product target, it is unable to adequately control the facial selectivity of the approach of the glycolate enolate revealed after nucleophile addition/[1,2]-Brook [33] rearrangement. Moreover, attempts to achieve separation of the resultant diastereomers at all synthetic intermediates in these two routes were unsuccessful. Thus, attention shifted to address the stereochemical issue.

Various approaches were considered to achieve a higher level of stereoselection in the three-component coupling reaction, which are summarized in Scheme 6 [34]. In light of the elegant precedent for overriding the moderate substrate bias from $(S)$-2methylbutanal (3) [26], auxiliary modification of the silyl glyoxylate structure to generalized type $1 \mathbf{c}$ could be envisioned. As hydrolysis of an ester would be required as a late-stage deprotection in any silyl glyoxylate-based approach, this modification would represent a relatively minor departure from ideality in the form of additional concession steps [35]. Alternatively, modification of the aldehyde partner, as in generalized type 16, was also considered. For this purpose, any stereocontrolling element $(\Omega$ or $\Psi$ in aldehyde types $16 \mathbf{a}$ and $16 \mathrm{~b}$, respectively) employed should meet the additional requirement that it be easily converted to a simple ethyl group to minimize the number of concession steps.

The auxiliary approach using silyl glyoxylates $\mathbf{1 c}$ ([Si] = TES or TBS, Scheme 6) proved to be suboptimal: despite the successful formation of the desired three-component coupling product, yields were low and poor stereochemical control was observed. Likewise, even the extreme steric demand of the tris(trimethylsilyl) group in aldehyde 16aa was insufficient for adequate stereocontrol in the three-component coupling reaction [34]. An additional branch point in the carbon backbone, such as in $\mathbf{1 6} \mathbf{b}$, was deemed necessary. The 1,3-dithiane group in aldehyde $\mathbf{1 6} \mathbf{b a}$ was conceived as a promising candidate for a

a) modify silyl glyoxylate

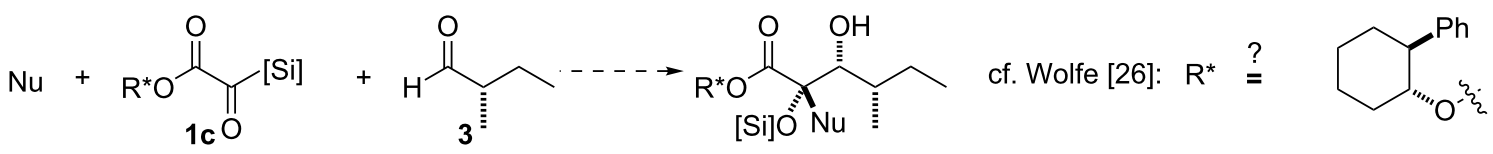

b) modify aldehyde

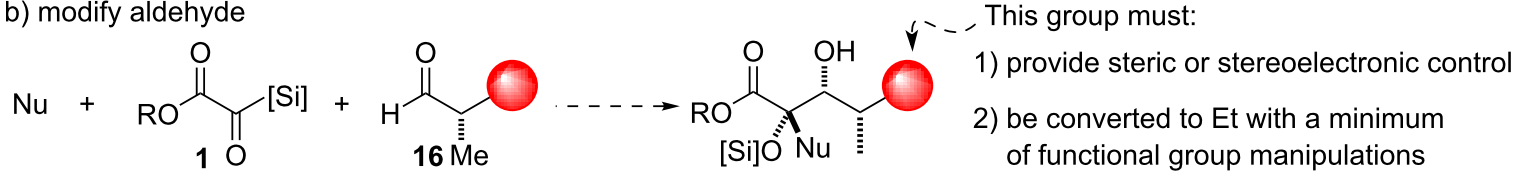

Generic examples:

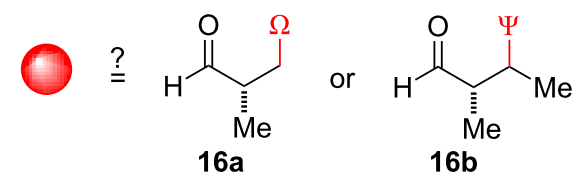
Specific examples: 
stereocontrolling element due to its large size and the wealth of precedents for single-step desulfurization to alkanes [36-40]. The racemic synthesis of the requisite aldehyde proved straightforward (see Supporting Information File 1). Most importantly, in initial three-component coupling reactions with vinyl nucleophile 4 and silyl glyoxylate 1a under previously optimized conditions, high efficiency was achieved along with excellent $(>20: 1)$ stereochemical control for the formation of threecomponent-coupling product 17 (Scheme 7) [41-44]. To verify that the dithiane was acting in the desired fashion, and to rule out chelation from one of the Lewis basic sulfur atoms, derivatization to a lactone was carried out. The dithiane was cleaved to the ketone 18, which underwent a 1,3-syn-selective reduction [45]. The resultant diol 19 was subjected to acidic conditions to effect cleavage of the tert-butyl ester and lactonization to afford 20. The NOESY and coupling-constant data of $\mathbf{2 0}$ was consistent with the role of the dithiane in $\mathbf{1 6 b a}$ as a nonchelating $R_{L}$ group that led to Felkin selectivity in the three-component coupling reaction.

The complete diastereochemical control exerted by the dithiane moiety of the aldehyde $\mathbf{1 6 b a}$ provided the impetus for exploring the use of a functionalized vinyl nucleophile in the threecomponent coupling reaction. Use of a more complex nucleophile would maintain the convergence of the overall synthesis, which was deemed important because (1) the route to the aldehyde component was becoming more involved; and (2) one or more additional steps for the removal of the directing group would be required. Thus, we developed a synthesis of a nucleophile that would allow the vast majority of the alternaric acid carbon skeleton to be installed through the three-component coupling reaction (Scheme 8). It began from the known allylic alcohol 21 [46], which was acetylated to afford ester 22 as prelude for reaction as a $\pi$-allyl electrophile with the Reformatsky reagent $\mathbf{2 3}$ derived from tert-butyl bromoacetate. The TMS-alkyne in $\mathbf{2 4}$ was deprotected with buffered TBAF to afford free alkyne $\mathbf{2 5}$, and the vinyl iodide $\mathbf{2 6}$ was generated by hydrozirconation/iodination of the free alkyne with Schwartz's reagent [47]. The vinyl nucleophile 27 could be generated by Knochel's Mg/I exchange [48] and employed successfully in the three-component-coupling reaction with silyl glyoxylate 1a and aldehyde $\mathbf{1 6 b a}$ to assemble $\mathbf{2 8}$, which contains the bulk of the carbon skeleton of alternaric acid. Remarkably, this highly convergent coupling allows the majority of the carbon backbone of the natural product to be assembled in a single complexity-building step.

With this gratifying result, a third distinct route to alternaric acid was enabled. Most importantly, this provides the first example of such a highly functionalized nucleophile being used in a silyl glyoxylate based three-component coupling reaction. Remaining tasks for the complete formation of the natural product include desulfurization [49], deprotection [50], and appendage of the pyrone moiety [24].

\section{Conclusion}

In conclusion, we have described the application of silyl glyoxylate three-component-coupling reactions as the central feature of three distinct approaches to the total synthesis of alternaric acid. By judicious choice of coupling partner and reaction conditions, it has been possible to achieve a formal synthesis, an analogous formal synthesis via an alternative<smiles>CCCCCC(C)C(=O)C(=O)OCCCC</smiles><smiles>C=CC(OC(C)(C)C)(C(O)C(C)C(C)=O)C(O)(O)C(C)=O</smiles>

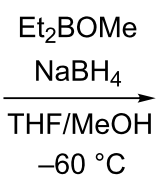

18 83\% yield

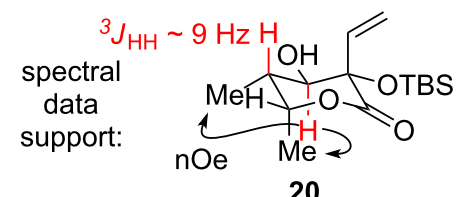

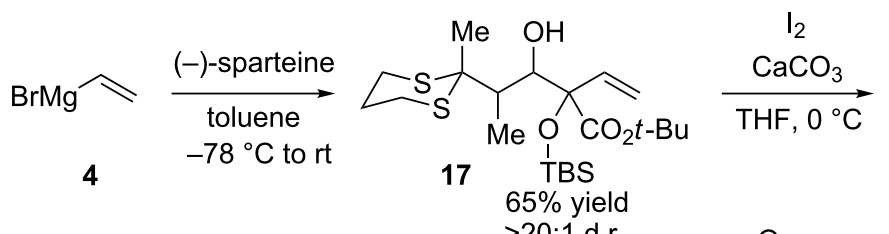

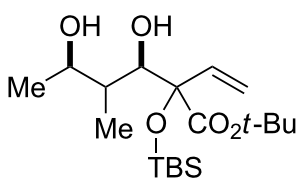<smiles>C1CC[In]CC1</smiles><smiles>C=CC1([Se-])C(=O)OC(C)C(C)[C@H]1O</smiles>

19 83\% yield

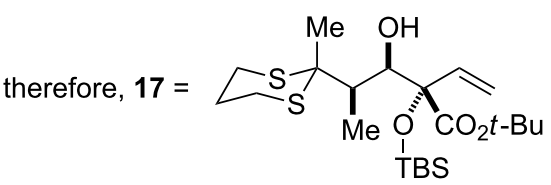




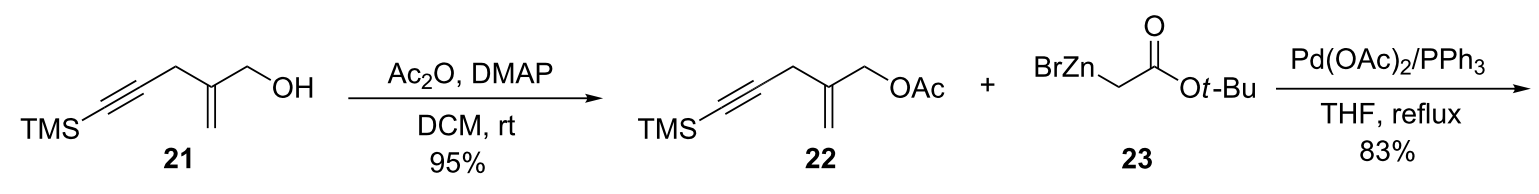

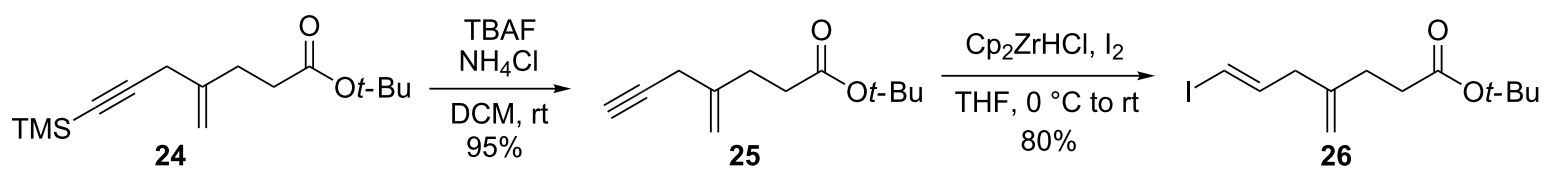

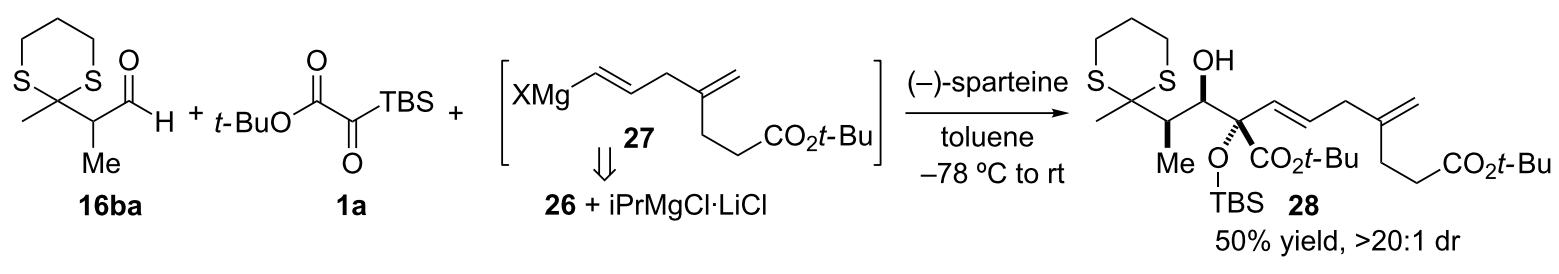

Scheme 8: Synthesis of a vinyl iodide for nucleophile generation and its use in a three-component coupling reaction.

route, and significant progress toward a third distinct route reliant on a highly functionalized nucleophile/electrophile combination for the construction of the majority of the natural product in a single step. In particular, this underscores the unique utility of silyl glyoxylates to serve as crucial linchpins for the coupling of a variety of nucleophile/electrophile pairs at a glycolic acid junction for the rapid development of molecular complexity.

\section{Supporting Information}

Contains additional tables and schemes for the three-component coupling reactions and approaches to address the stereochemical problem. Also contains experimental procedures, characterization, and spectral data.

\section{Supporting Information File 1}

Additional data.

[http://www.beilstein-journals.org/bjoc/content/ supplementary/1860-5397-9-19-S1.pdf]

\section{Acknowledgements}

The project described was supported by Award R01 GM084927 from the National Institute of General Medical Sciences. We thank Rebecca Cuellar for early exploratory studies and Justin Malinowski and Michael Corbett (UNC) for acquiring massspectral data.

\section{References}

1. Nicolaou, K. C.; Hale, C. R. H.; Nilewski, C.; loannidou, H. A. Chem. Soc. Rev. 2012, 41, 5185-5238. doi:10.1039/c2cs35116a

2. Rapid complexity generation in natural product total synthesis. Chem. Soc. Rev. 2009, 38, 2969-3276. doi:10.1039/b920767h

See the thematic issue for a recent compilation of reviews on this topic in the context of natural-products synthesis.

3. Nicewicz, D. A.; Johnson, J. S. J. Am. Chem. Soc. 2005, 127 , 6170-6171. doi:10.1021/ja043884I

4. Linghu, X.; Satterfield, A. D.; Johnson, J. S. J. Am. Chem. Soc. 2006, 128, 9302-9303. doi:10.1021/ja062637+

5. Nicewicz, D. A.; Brétéché, G.; Johnson, J. S.; Bryan, C.; Lautens, M. Org. Synth. 2008, 85, 278-286.

6. Nicewicz, D. A.; Satterfield, A. D.; Schmitt, D. C.; Johnson, J. S. J. Am. Chem. Soc. 2008, 130, 17281-17283. doi:10.1021/ja808347q

7. Greszler, S. N.; Johnson, J. S. Org. Lett. 2009, 11, 827-830. doi:10.1021/ol802828d

8. Greszler, S. N.; Johnson, J. S. Angew. Chem., Int. Ed. 2009, 48, 3689-3691. doi:10.1002/anie.200900215

9. Schmitt, D. C.; Johnson, J. S. Org. Lett. 2010, 12, 944-947. doi:10.1021/ol9029353

10. Steward, K. M.; Johnson, J. S. Org. Lett. 2010, 12, 2864-2867. doi:10.1021/ol100996w

11. Boyce, G. R.; Johnson, J. S. Angew. Chem., Int. Ed. 2010, 49, 8930-8933. doi:10.1002/anie.201003470

12. Greszler, S. N.; Malinowski, J. T.; Johnson, J. S. J. Am. Chem. Soc. 2010, 132, 17393-17395. doi:10.1021/ja108848d

13. Greszler, S. N.; Malinowski, J. T.; Johnson, J. S. Org. Lett. 2011, 13, 3206-3209. doi:10.1021/ol2011192

14. Schmitt, D. C.; Lam, L.; Johnson, J. S. Org. Lett. 2011, 13, 5136-5139. doi:10.1021/ol202002r

15. Boyce, G. R.; Liu, S.; Johnson, J. S. Org. Lett. 2012, 14, 652-655. doi:10.1021/ol2033527 
16. Schmitt, D. C.; Malow, E. J.; Johnson, J. S. J. Org. Chem. 2012, 77, 3246-3251. doi:10.1021/jo202679u

17. Bolm, C.; Kasyan, A.; Heider, P.; Saladin, S.; Drauz, K.; Günther, K.; Wagner, C. Org. Lett. 2002, 4, 2265-2267. doi:10.1021/ol025911n

18. Lettan, R. B.; Galliford, C. V.; Woodward, C. C.; Scheidt, K. A. J. Am. Chem. Soc. 2009, 131, 8805-8814. doi:10.1021/ja808811u

19. Yao, M.; Lu, C. D. Org. Lett. 2011, 13, 2782-2785. doi:10.1021/ol201029b

20. Boyce, G. R.; Greszler, S. N.; Johnson, J. S.; Linghu, X.; Malinowski, J. T.; Nicewicz, D. A.; Satterfield, A. D.; Schmitt, D. C.; Steward, K. M. J. Org. Chem. 2012, 77, 4503-4515. doi:10.1021/jo300184h Perspective article.

21. Brian, P. W.; Curtis, P. J.; Hemming, H. G.; Unwin, C. H.; Wright, J. M. Nature 1949, 164, 534. doi:10.1038/164534a0

22. Brian, P. W.; Curtis, P. J.; Hemming, H. G.; Jefferys, E. G.; Unwin, C. H.; Wright, J. M. J. Gen. Microbiol. 1951, 5, 619-632. doi:10.1099/00221287-5-4-619

23. Bartels-Keith, J. R. J. Chem. Soc. 1960, 1662-1665. doi:10.1039/JR9600001662

24. Tabuchi, H.; Hamamoto, T.; Miki, S.; Tejima, T.; Ichihara, A. J. Org. Chem. 1994, 59, 4749-4759. doi:10.1021/jo00096a016

25. Trost, B. M.; Probst, G. D.; Schoop, A. J. Am. Chem. Soc. 1998, 120 9228-9236. doi:10.1021/ja981540n

26. Giampietro, N. C.; Kampf, J. W.; Wolfe, J. P. J. Am. Chem. Soc. 2009, 131, 12556-12557. doi:10.1021/ja905930s

27. Anelli, P. L.; Montanari, F.; Quici, S.; Nonoshita, K.; Yamamot, H. Org. Synth. 1990, 69, 212.

28. Our results are consistent with the additions of nucleophiles to 3 (cf. [24-26]). For rare, successful examples of Me/Et differentiation, see $[29,30]$.

29. Evans, D. A.; Kozlowski, M. C.; Burgey, C. S.; MacMillan, D. W. C. J. Am. Chem. Soc. 1997, 119, 7893-7894. doi:10.1021/ja971521y

30. Copeland, G. T.; Miller, S. J. J. Am. Chem. Soc. 2001, 123, 6496-6502. doi:10.1021/ja0108584

31. The precise role of the (-)-sparteine is uncertain at this time. It is possible that the Lewis basic nitrogens chelate the magnesium, facilitating the reversibility of the aldolization step leading to high syn-selectivity. See [20], footnote 42.

32. Blakemore, P. R. J. Chem. Soc., Perkin Trans. 1 2002, 2563-2585. doi:10.1039/B208078H

33. Brook, A. G. Acc. Chem. Res. 1974, 7, 77-84. doi:10.1021/ar50075a003

34. The results of efforts with silylglyoxylates 1c, and other specific examples for the identities of $\Omega$ and $\Psi$, were also pursued. See Supporting Information File 1 for additional details.

35. Gaich, T.; Baran, P. S. J. Org. Chem. 2010, 75, 4657-4673. doi:10.1021/j01006812

36. Yang, T.-K.; Lee, D.-S.; Haas, J. Raney Nickel. e-EROS Encyclopedia of Reagents for Organic Synthesis; John Wiley \& Sons: New York, N. Y., 2006. doi:10.1002/047084289X.rr001.pub2

37. Back, T. G.; Baron, D. L.; Yang, K. J. Org. Chem. 1993, 58, 2407-2413. doi:10.1021/jo00061a011

38. Chan, M. C.; Cheng, K. M.; Ho, K. M.; Ng, C. T.; Yam, T. M.; Wang, B. S. L.; Luh, T. Y. J. Org. Chem. 1988, 53, 4466-4471. doi:10.1021/jo00254a009

39. Becker, S.; Fort, Y.; Vanderesse, R.; Caubere, P. Tetrahedron Lett. 1988, 29, 2963-2966. doi:10.1016/0040-4039(88)85058-5

40. Becker, S.; Fort, Y.; Caubere, P. J. Org. Chem. 1990, 55, 6194-6198. doi:10.1021/jo00312a029
41. Aldehyde 16ba has previously been used in aldol reactions; no comment on the diastereoselectivity was made, likely because it was immaterial in those applications (see $[42,43]$ ).

42. Kim, H.; Baker, J. B.; Lee, S.-U.; Park, Y.; Bolduc, K. L.; Park, H.-B.; Dickens, M. G.; Lee, D.-S.; Kim, Y.; Kim, S. H.; Hong, J. J. Am. Chem. Soc. 2009, 131, 3192-3194. doi:10.1021/ja8101192

43. Kim, H.; Baker, J. B.; Park, Y.; Park, H. B.; DeArmond, P. D.; Kim, S. H.; Fitzgerald, M. C.; Lee, D.-S.; Hong, J. Chem.-Asian J. 2010, 5, 1902-1910. doi:10.1002/asia.201000147

44. Ward, D. E.; Kazemeini, A. J. Org. Chem. 2012, 77, 10789-10803. doi:10.1021/jo302142v

While this manuscript was in review, a thorough study of the stereochemical outcomes using structurally related aldehydes was reported.

45. Chen, K.-M.; Gunderson, K. G.; Hardtmann, G. E.; Prasad, K.; Repic, O.; Shapiro, M. J. Chem. Lett. 1987, 16, 1923-1926. doi:10.1246/cl.1987.1923

46. Renaud, J.-L.; Aubert, C.; Malacria, M. Tetrahedron Lett. 1999, 40, 5015-5018. doi:10.1016/S0040-4039(99)00981-8

47. Reichard, H. A.; Rieger, J. C.; Micalizio, G. C. Angew. Chem., Int. Ed. 2008, 47, 7837-7840. doi:10.1002/anie.200803031

48. Ren, H.; Krasovskiy, A.; Knochel, P. Org. Lett. 2004, 6, 4215-4217. doi:10.1021/ol048363h

49. Initial attempts to effect this transformation in a model system have demonstrated that this may not be as straightforward as anticipated. See Supporting Information File 1 for details.

50. Likewise, this may prove more difficult than anticipated; acid-promoted hydrolysis of the tert-butyl esters and silyl ether was planned, due to the success of such a transformation with the simpler substrate $\mathbf{5}$, as in Scheme 3. However, substrate $\mathbf{2 8}$ tends to decompose when treated under a variety of acidic conditions.

\section{License and Terms}

This is an Open Access article under the terms of the Creative Commons Attribution License (http://creativecommons.org/licenses/by/2.0), which permits unrestricted use, distribution, and reproduction in any medium, provided the original work is properly cited.

The license is subject to the Beilstein Journal of Organic Chemistry terms and conditions: (http://www.beilstein-journals.org/bjoc)

The definitive version of this article is the electronic one which can be found at: doi:10.3762/bjoc.9.19 